\title{
PERMODELAN SISTEM FIXED TIME CONTROLLER DAN SEMI ACTUATED CONTROLLER PADA SIMPANG EXIT TOLL GONDANGREJO MENGGUNAKAN PROGRAM SIMULASI PTV VISSIM
}

\author{
Jusuf Fernando Hasiholan ${ }^{1}$, Budi Yulianto ${ }^{2}$, Setiono ${ }^{3)}$ \\ 1) Mahasiswa Fakultas Teknik, Prodi Teknik Sipil, Universitas Sebelas Maret \\ 2), 3) Pengajar Fakultas Teknik, Prodi Teknik Sipil, Universitas Sebelas Maret \\ J1. Ir. Sutami No. 36A, Kentingan, Surakarta 57126; Telp. (0271) 647069, Fax 634524 \\ Email: jusuf hasiholan1999@,student.uns.ac.id
}

\begin{abstract}
The accessibility of toll roads and non-toll roads must be taken into account by the government, especially by the Department of Transportation because the provision of such access will create a new road intersection as a result of the meeting between public roads and toll road sections, hereinafter referred as toll exit intersections. The location chosen as a review of this research is the Gondangrejo Toll Exit intersection, which is a signalized intersection that uses a Fixed Time Controller system in the operation of its traffic lights. The characteristics of this intersection are different from the intersection in urban areas where there are differences in the amount of traffic flow on toll roads and non-toll roads. This study aims to model and analyze the performance of the Gondangrejo Toll Exit intersection using the Fixed Time Controller and Semi Actuated Controller systems using the PTV VISSIM simulation program. The process of calibration and validation in the base model is carried out to get accurate and close to real results. In the calibration process, the Geoffrey E. Havers (GEH) statistical test was carried out on the traffic flow at the intersection arms to determine whether the model had been calibrated. Meanwhile, in the validation process, a t-test was carried out on the maximum queue length at every 10-minute interval and a relative difference test for $L V$ travel time to determine whether the model had been validated. From the modeling and analysis that has been done, it can be concluded that the Fixed Time Controller system with an early cut-off movement has a significant effect on improving the performance of the Gondangrejo Toll Exit Interchange because of the longer green time duration on major roads, while the use of the Semi Actuated Controller system with the normal phase movement does not have a significant effect because at every cycle time there are vehicles from the minor road (east direction). Semi Actuated Controller can improve intersection performance when used in conditions where in every cycle time there are not always vehicles from minor roads.
\end{abstract}

Keywords: Early Cut-off, GEH Statistical Test, Gondangrejo Toll Exit Intersection, PTV VISSIM, Semi Actuated Controller

\begin{abstract}
Abstrak
Aksesibilitas dari jalan tol dan jalan non tol harus dijadikan perhatian oleh pemerintah khususnya oleh Dinas Perhubungan sebab penyediaan akses tersebut akan menciptakan suatu persimpangan jalan baru dari hasil pertemuan antara jalan umum dan ruas jalan tol yang selanjutnya disebut sebagai simpang exit toll. Lokasi yang dipilih sebagai tinjauan pada penelitan ini adalah Simpang Exit Toll Gondangrejo yaitu simpang tiga bersinyal yang menggunakan sistem Fixed Time Controller dalam pengoperasian lampu lalu lintasnya. Karakteristik pada persimpangan ini memiliki perbedaan dengan persimpangan di perkotaan dimana terdapat perbedaan jumlah arus lalu lintas pada jalan tol dan jalan non tol. Penelitian ini bertujuan untuk memodelkan dan menganalisis kinerja Simpang Exit Toll Gondangrejo menggunakan sistem Fixed Time Controller dan Semi Actuated Controller menggunakan program simulasi PTV VISSIM. Proses kalibrasi dan validasi pada base model dilakukan untuk mendapatkan hasil yang akurat dan mendekati kenyataan. Pada proses kalibrasi dilakukan uji statistik Geoffrey E. Havers $(\mathrm{GEH})$ terhadap arus lalu lintas di lengan-lengan simpang untuk mengetahui apakah model telah terkalibrasi. Sedangkan pada proses validasi dilakukan uji t terhadap panjang antrian maksimum tiap interval 10 menit dan uji perbedaan relative terhadap waktu perjalanan LV untuk mengetahui apakah model telah tervalidasi. Dari pemodelan dan analisis yang telah dilakukan, dapat disimpulkan bahwa sistem Fixed Time Controller dengan pergerakan early cut-off berpengaruh signifikan terhadap peningkatan kinerja Simpang Exit Tol Gondangrejo karena durasi waktu hijau yang lebih panjang pada jalan mayor, sedangkan penggunaan sistem Semi Actuated Controller dengan pergerakan fase normal tidak berpengaruh signifikan karena pada setiap waktu siklus terdapat kendaraan dari jalan minor (arah timur). Semi Actuated Controller dapat meningkatkan kinerja simpang apabila digunakan pada kondisi dimana dalam setiap waktu siklus tidak selalu ada kendaraan dari jalan minor.
\end{abstract}

Kata Kunci : Early Cut-off, PTV VISSIM, Semi Actuated Controller, Simpang Exit Tol Gondangrejo, Uji Statistik GEH

\section{PENDAHULUAN}

Saat ini pembangunan infrastruktur jalan tol di seluruh wilayah Provinsi Jawa Tengah dan Jawa Timur sedang giat dilaksanakan, termasuk diantaranya pembangunan Jalan Tol Solo-Ngawi yang telah dibuka pada 11 November 2019. Jalan Tol Solo-Ngawi merupakan jalan tol yang mempunyai panjang sekitar $90 \mathrm{~km}$ yang memfasilitasi perjal- 
anan darat antara Kota Surakarta, Jawa Tengah dengan Kabupaten Ngawi, Jawa Timur. Jalan tol ini melewati beberapa wilayah di Provinsi Jawa Tengah dan Jawa Timur yang diantaranya adalah Kabupaten Boyolali, Kabupaten Karanganyar, Kabupaten Sragen, dan Kabupaten Ngawi. Jalan tol ini merupakan bagian dari jaringan Jalan Tol Trans Jawa yang terhubung dengan Jalan Tol Semarang-Solo dan Jalan Tol Ngawi-Kertosono.

Aksesibilitas jalan tol dari dan menuju jalan umum harus dijadikan perhatian oleh pemerintah khususnya oleh Dinas Perhubungan sebab penyediaan akses tersebut akan menciptakan suatu persimpangan jalan baru dari hasil pertemuan antara jalan umum dan ruas jalan tol. Simpang Exit Toll Gondangrejo merupakan simpang pertemuan antara Jalan Raya Solo-Purwodadi dengan Gerbang Exit Toll Gondangrejo. Simpang ini memiliki tiga pendekat dan difasilitasi dengan lampu lalu lintas yang menggunakan sistem fixed time controller. Simpang Exit Toll Gondangrejo terletak di ruas Jalan Raya Solo-Purwodadi tepatnya di Jalan Raya Jetak Kelurahan Jetak, Kecamatan Wonorejo, Kabupaten Karanganyar. Simpang Exit Toll Gondangrejo ini perlu mendapat atensi sebab adanya perbedaan yang signifikan pada arus lalu lintas antara Jalan Raya Solo-Purwodadi yang merupakan jalan mayor dengan arus lalu lintas tinggi dengan Jalan keluar masuk Exit Toll Gondangrejo yang memiliki arus lalu lintas yang relatif rendah. Perbedaan pada arus lalu lintas tersebut memerlukan perencanaan manajemen rekayasa lalu lintas yang diharapkan mampu mengefektifkan kinerja Simpang Exit Toll Gondangrejo.

Untuk mengukur keakuratan dari sebuah simulasi dengan kondisi nyata pada lalu lintas salah satu pendekatan yang paling banyak digunakan adalah penggunaan simulasi lalu lintas. Variasi yang diterapkan pada studi ini adalah menggunakan program simulasi PTV VISSIM. PTV VISSIM merupakan perangkat lunak untuk memodelkan lalu lintas berdasarkan perilaku pengguna jalan yang dapat digunakan untuk menganalisis dan melakukan optimalisasi pengaturan arus lalu lintas. Program simulasi PTV VISSIM ini bisa memodelkan kondisi lapangan secara 2D dan 3D, sehingga bisa mempermudah pengguna dalam menganalisis simpang bersinyal Exit Toll Gondangrejo.

\section{DASAR TEORI}

\section{Simpang}

Simpang merupakan titik pertemuan arus kendaraan dari daerah asal menuju daerah tujuan. Simpang adalah suatu area kritis pada jaringan jalan dimana dua ruas jalan atau lebih saling bertemu sehingga menjadi tempat terjadinya konflik pergerakan dan kemacetan. Pertemuan sebidang, pertemuan tidak sebidang, dan persilangan jalan adalah tiga macam pertemuan jalan yang dikenal pada sistem transportasi.

\section{Lampu Lalu Lintas}

Menurut UU nomor 22 tahun 2009 tentang LLAJ, lampu lalu lintas atau sering disebut dengan Alat Pemberi Isyarat Lalu Lintas (APILL) adalah lampu yang berada pada kanan kiri lengan suatu persimpangan jalan, berupa tiang dengan tiga buah lampu dengan warna merah, kuning dan hijau yang berfungsi untuk mengatur dan mengendalikan arus lalu lintas.

\section{Kinerja Simpang Bersinyal}

Menurut Manual Kapasitas Jalan Indonesia (1997), untuk menghindari kemacetan simpang akibat padatnya arus lalu lintas maka dipergunakan sinyal lalu lintas, agar mempertahankan suatu kapasitas tertentu, bahkan saat kondisi lalu lintas berada di jam puncak. Arus Jenuh, Kapasitas Simpang, Derajat kejenuhan, Panjang Antrian, Kendaraan Henti dan Tundaan adalah beberapa parameter yang digunakan sebagai acuan pada perhitungan kinerja simpang dengan metode MKJI.

\section{Pengaturan Pergerakan pada Simpang dengan Lampu Lalu Lintas}

Terdapat beberapa teknik untuk mengatur pergerakan berdasarkan arus lalu lintas yang belok kanan pada simpang dengan lampu lalu lintas yaitu Mengizinkan Pergerakan, Membatasi Pergerakan, Memisahkan Pergerakan (Pemutusan Cepat (Early Cut Off), Awal yang Terlambat (Late Start), dan Fase Khusus Belok Kanan.

\section{Program Simulasi PTV VISSIM}

VISSIM merupakan program simulasi mikroskopis dan makroskopis terkemuka untuk pemodelan transportasi multimoda operasi yang dikembangkan oleh PTV Group VISSIM mampu melakukan simulasi berbagai jenis kendaraan pada berbagai kondisi lalu lintas yang mengacu pada model Wiedemann. 


\section{Kalibrasi dan Validasi PTV VISSIM}

Kalibrasi adalah proses menyesuaikan parameter tertentu yang dilakukan secara berulang agar nilai hasil simulasi sesuai dengan data hasil observasi di lapangan. Parameter kalibrasi merupakan hal-hal yang berkaitan dengan perilaku pengemudi. Dalam penelitian ini, jumlah arus lalu lintas di lengan-lengan simpang digunakan sebagai variabel pembanding untuk mengetahui signifikansi perbedaan antara hasil simulasi dan data hasil pengamatan langsung di lapangan (Yulianto B dan Setiono, 2013).

Validasi merupakan proses agar peneliti dapat menentukan apakah model simulasi lalu lintas yang dibuat dapat merepresentasikan kenyataan yang ada dengan akurat. Model simulasi lalu lintas dikatakan valid apabila output yang dihasilkan model dapat mendekati data pengamatan langsung hasil kejadian yang ada di lapangan. Proses validasi melibatkan perbandingan hasil simulasi pada program (output) dengan data pengamatan langsung yang didapatkan dari studi lapangan. Travel Time (detik) dan Panjang Antrian (meter) merupakan kinerja simpang yang dipilih sebagai variabel pembanding antara hasil pemodelan dengan hasil pengamatan langsung di lapangan (Yulianto dan Setiono, 2013).

Metode untuk mengukur kesesuaian (goodness of fit) antara hasil simulasi dan hasil observasi dalam proses kalibrasi dan validasi pada penelitian ini yaitu (UK Highway Agency, 2015 dan Department for Transport, 2020):

1. Perbedaan Relatif

Perbedaan relatif adalah perbedaan yang diukur dengan membandingkan nilai perbedaan mutlak dengan nilai observasi sehingga tidak memiliki satuan (unit). Nilai perbedaan mutlak dapat dihitung dengan persamaan [1] berikut

Perbedaan Relatif $=\frac{(\text { Nilai Model }- \text { Nilai Observasi })}{(\text { Nilai Observasi })}$

2. Statistik GEH (Geoffrey E. Havers)

Statistik GEH adalah persamaan empiris yang telah digunakan dalam rekayasa lalu lintas dan perencanaan transportasi untuk membandingkan kesesuaian jumlah arus lalu lintas hasil model dan hasil observasi. Nilai GEH dihitung menggunakan persamaan [2].

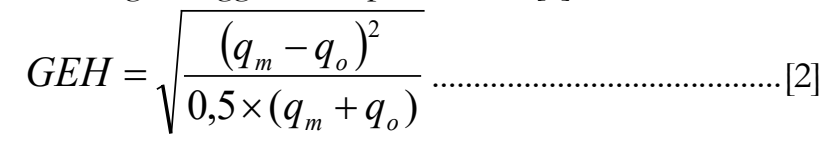

dengan:

$\mathrm{q}_{\mathrm{m}}=$ arus lalu lintas pada model

$\mathrm{q}_{\mathrm{o}}=$ arus lalu lintas pada pengamatan langsung di lapangan

\section{Independent sample t-test}

Independent sample t-test diperuntukan sebagai acuan yang menentukan apakah dua sampel yang tidak sama memiliki rata-rata yang berbeda. Uji t untuk varian yang sama (equal variance) menggunakan rumus Polled Varians:

$$
\begin{aligned}
& t=\frac{\bar{x}_{1}-\bar{x}_{2}}{\frac{\left(n_{1}-1\right) S_{1}+\left(n_{2}\right)}{n_{1}+n_{2}+2}\left(\frac{1}{n_{1}}+\frac{1}{n_{2}}\right)} \\
& \text { dengan: } \\
& \overline{\mathrm{x}_{1}} \quad=\text { rerata sampel } 1 \\
& \overline{\mathrm{x}_{2}} \quad=\text { rerata sampel } 2 \\
& \mathrm{~S}_{1} \quad=\text { deviasi standar sampel } 1 \\
& \mathrm{~S}_{2} \quad=\text { deviasi standar sampel } 2 \\
& \mathrm{~S}_{1}^{2} \quad=\text { varians sampel } 1 \\
& \mathrm{~S}_{2}^{2} \quad=\text { varians sampel } 2 \\
& \mathrm{n}_{1} \quad=\text { jumlah data sampel } 1 \\
& \mathrm{n}_{2} \quad=\text { jumlah data sampel } 2
\end{aligned}
$$


Cara mengetahui signifikansi hasil uji t, yaitu dengan melihat perbandingan $\mathrm{T}_{\text {hitung }}$ dengan $\mathrm{T}_{\text {tabel }}$ (two-tailed) dan hasil nilai $\mathrm{P}$ (two-tailed). Apabila nilai $\mathrm{T}_{\text {hitung }}<\mathrm{T}_{\text {tabel }}$ (two-tailed) dan hasil nilai $\mathrm{P}($ two-tailed) $>0,05$, maka perbedaan tidak signifikan.

\section{METODE PENELITIAN}

\section{Pengumpulan Data}

Dalam penyusunan studi, salah satu tahap terpenting dalam menyelesaikan penelitian ini adalah tahap pengumpulan data. Semua data yang didapat dari pengumpulan data sekunder maupun data primer (survei lapangan) selanjutnya digunakan untuk input dalam proses perhitungan dan permodelan simpang bersinyal Exit Toll Gondangrejo. Dalam penelitian ini yang digunakansebagai metode pengumpulan data adalah sebagai berikut:

1. Survei Geometrik Jalan

2. Survei Pencacahan Lalu Lintas

3. Survei Kecepatan Kendaraan

4. Survei Waktu Perjalanan

5. Survei Panjang Antrian

6. Survei Fase Lampu Lalu Lintas

\section{Analisis Data}

Pembuatan model Simpang Exit Toll Gondangrejo dibuat berdasarkan data-data yang sudah didapatkan untuk selanjutnya dimodelkan menggunakan program simulasi PTV VISSIM. Analisis dari model tersebut akan menghasilkan parameter kinerja simpang berupa panjang antrian, waktu perjalanan dan tundaan.

\section{Kalibrasi dan Validasi Base Model}

Pada penelitian ini, kalibrasi dilakukan dengan cara mengubah parameter-parameter Driving Behaviors yang disesuaikan dengan memperhatikan penelitian-penelitian yang sudah pernah membahas kalibrasi dan validasi menggunakan program simulasi PTV VISSIM. Parameter Driving Behavior yang dikalibrasi dalam penelitian ini adalah Following behavior, Average standstill distance, Lateral behavior, Desired position at free flow, Default behavior when overtaking vehicle on the same lane.

\section{HASIL DAN PEMBAHASAN}

\section{Hasil Kalibrasi dan Validasi}

Untuk mengetahui signifikasi perbedaan antara jumlah arus lalu lintas hasil model dan hasil observasi perlu dilakukan uji statistik GEH terhadap arus lalu lintas di lengan-lengan simpang. Jika nilai GEH kurang dari 5 (GEH > 5) maka uji statistik GEH dinyatakan dapat diterima. Pada tabel 1 sudah disajikan hasil uji statistik GEH pada jam puncak dan jam tidak puncak.

Tabel 1. Hasil uji GEH arus lalu lintas pada jam puncak dan tidak puncak

\begin{tabular}{ccccccccc}
\hline \multirow{2}{*}{ Lokasi } & \multicolumn{4}{c}{ Jam Puncak } & \multicolumn{4}{c}{ Jam Tidak Puncak } \\
\cline { 2 - 9 } & $\begin{array}{c}\text { Rata- } \\
\text { Rata }\end{array}$ & $\begin{array}{c}\text { q } \\
\text { Observasi }\end{array}$ & $\begin{array}{c}\text { Nilai } \\
\text { GEH }\end{array}$ & $\begin{array}{c}\text { Ket- } \\
\text { erangan }\end{array}$ & Rata-Rata & $\begin{array}{c}\text { q } \\
\text { Observasi }\end{array}$ & $\begin{array}{c}\text { Nilai } \\
\text { GEH }\end{array}$ & Keterangan \\
\hline 1 & 2535 & 2550 & 1.16 & Diterima & 1589 & 1572 & 0.43 & Diterima \\
2 & 89 & 91 & 0.00 & Diterima & 83 & 87 & 0.43 & Diterima \\
3 & 1393 & 1410 & 0.08 & Diterima & 1017 & 1015 & 0.06 & Diterima \\
4 & 1356 & 1373 & 0.05 & Diterima & 990 & 1005 & 0.47 & Diterima \\
5 & 61 & 62 & 1.22 & Diterima & 103 & 89 & 1.43 & Diterima \\
6 & 2453 & 2479 & 0.66 & Diterima & 1527 & 1580 & 1.34 & Diterima \\
\hline
\end{tabular}

Tabel 1 menunjukan hasil Uji statistik GEH terhadap arus lalu lintas di lengan-lengan simpang pada jam puncak dan tidak puncak kurang dari lima sehingga uji statistik GEH dinyatakan dapat diterima yang berarti arus lalu lintas output model dan observasi lapangan pada jam puncak dan tidak puncak tidak terdapat perbedaan secara signifikan. Proses validasi dilakukan setelah kalibrasi selesai dilakukan, validasi dilakukan untuk mengerti apakah model yang dibuat sesuai dengan kondisi aktual di lapangan. Panjang antrian maksimum tiap interval 10 menit dan waktu perjalanan menjadi variabel pembanding yang digunakan dalam proses validasi. Uji kesesuaian yang dilakukan 
terhadap panjang antrian maksimum adalah uji t dengan hipotesis nol $\left(\mathrm{H}_{0}\right)$ yang menjelaskan bahwa tidak ada perbedaan signifikan pada panjang antrian maksimum output model dan hasil observasi. Pada Tabel 2 dan 3 ditampilkan hasil uji t panjang antrian maksimum tiap interval 10 menit pada jam puncak dan jam tidak puncak.

Tabel 2. Uji T-test panjang antrian jam puncak

\begin{tabular}{|c|c|c|c|c|c|c|c|c|}
\hline \multirow{2}{*}{ No } & \multirow{2}{*}{$\begin{array}{l}\text { Kaki Sim- } \\
\text { pang }\end{array}$} & \multirow{2}{*}{$\begin{array}{l}\text { Interval } 10 \\
\text { menit ke }\end{array}$} & \multicolumn{2}{|c|}{ Panjang Antrian Maksimum } & \multirow{2}{*}{$\begin{array}{l}\text { Nilai t } \\
\text { Tabel }\end{array}$} & \multirow{2}{*}{$\begin{array}{l}\text { Nilai t } \\
\text { Hitung }\end{array}$} & \multirow{2}{*}{ Nilai P } & \multirow{2}{*}{$\begin{array}{c}\text { Ket- } \\
\text { erangan }\end{array}$} \\
\hline & & & Model & Observasi & & & & \\
\hline \multirow{6}{*}{1} & \multirow{6}{*}{ Selatan } & $07: 24: 44$ & 59 & 55 & \multirow{6}{*}{2,28} & \multirow{6}{*}{1,6812} & \multirow{6}{*}{0,123} & \multirow{6}{*}{ Diterima } \\
\hline & & $07: 34: 44$ & 65 & 64 & & & & \\
\hline & & $07: 44: 44$ & 60 & 58 & & & & \\
\hline & & $07: 54: 44$ & 62 & 54 & & & & \\
\hline & & 08:04:44 & 60 & 54 & & & & \\
\hline & & $08: 14: 44$ & 63 & 63 & & & & \\
\hline
\end{tabular}

Tabel 3 Uji T-test panjang antrian jam puncak

\begin{tabular}{|c|c|c|c|c|c|c|c|c|}
\hline \multirow[b]{2}{*}{ No } & \multirow[b]{2}{*}{ Kaki Simpang } & \multirow{2}{*}{$\begin{array}{l}\text { Interval } \\
10 \text { menit } \\
\text { ke }\end{array}$} & \multicolumn{2}{|c|}{ Panjang Antrian Maksimum } & \multirow{2}{*}{$\begin{array}{l}\text { Nilai t } \\
\text { Tabel }\end{array}$} & \multirow{2}{*}{$\begin{array}{l}\text { Nilai t } \\
\text { Hitung }\end{array}$} & \multirow[b]{2}{*}{ Nilai $\mathbf{P}$} & \multirow{2}{*}{$\begin{array}{c}\text { Ket- } \\
\text { erangan }\end{array}$} \\
\hline & & & Model & Observasi & & & & \\
\hline \multirow{6}{*}{1} & \multirow{6}{*}{ Selatan } & 09:11:10 & 55 & 52 & \multirow{6}{*}{2,28} & \multirow{6}{*}{1,14} & \multirow{6}{*}{0,28} & \multirow{6}{*}{ Diterima } \\
\hline & & 09:21:10 & 56 & 58 & & & & \\
\hline & & 09:31:10 & 68 & 60 & & & & \\
\hline & & 09:41:10 & 61 & 58 & & & & \\
\hline & & 09:51:10 & 56 & 53 & & & & \\
\hline & & 10:01:10 & 62 & 60 & & & & \\
\hline
\end{tabular}

Tabel 2 dan 3 menunjukan hasil Uji t pada panjang antrian maksimum jam puncak dan tidak puncak di lengan simpang selatan berupa thitung $<\mathrm{t}_{\text {tabel }}$ serta $\mathrm{P}$ (two-tailed) $>0,05$ sehingga $\mathrm{H}_{0}$ dinyatakan dapat diterima yang berarti panjang antrian maksimum output model dan observasi lapangan pada jam puncak tidak terdapat perbedaan secara signifikan.

Untuk validasi atau uji kesesuaian terhadap waktu perjalanan digunakan uji perbedaan relatif. Jika persentase perbedaan waktu perjalanan output model dan hasil observasi kurang dari sama dengan 15\% (persentase perbedaan $\leq 15 \%)$ maka uji perbedaan relatif dinyatakan dapat diterima. Tabel 4 menyajikan hasil uji perbedaan relatif waktu perjalanan pada jam sibuk dan jam tidak sibuk.

Tabel 4. Hasil uji relatif waktu tempuh jam puncak dan tidak puncak

\begin{tabular}{|c|c|c|c|c|c|c|c|c|}
\hline \multirow{3}{*}{$\begin{array}{l}\text { Rute Perjal- } \\
\text { anan }\end{array}$} & \multicolumn{3}{|c|}{ Jam Puncak } & & \multicolumn{4}{|c|}{ Jam Tidak Puncak } \\
\hline & \multicolumn{2}{|c|}{ Waktu Perjalanan } & \multirow{2}{*}{$\begin{array}{l}\text { Nilai } \\
\text { Perbe- } \\
\text { daan } \\
\text { relatif }\end{array}$} & \multirow[b]{2}{*}{ Ket. } & \multicolumn{2}{|c|}{ Waktu Perjalanan } & \multirow{2}{*}{$\begin{array}{c}\text { Nilai } \\
\text { Perbe- } \\
\text { daan } \\
\text { Relatif }\end{array}$} & \multirow[b]{2}{*}{ Keterangan } \\
\hline & Model & Observasi & & & Model & Observasi & & \\
\hline Selatan-Utara & 101,6 & 101 & $1 \%$ & Diterima & 94.4 & 82.8 & $14 \%$ & Diterima \\
\hline Utara-Selatan & 129,6 & 138 & $6 \%$ & Diterima & 98.6 & 93.3 & $6 \%$ & Diterima \\
\hline
\end{tabular}

Tabel 4 menunjukan bahwa persentase perbedaan relatif waktu perjalanan rata-rata pada jam tidak puncak dari arah utara dan selatan kurang dari sama dengan 15\% sehingga uji perbedaan relatif dinyatakan diterima.

\section{Permodelan Simpang Exit Toll Gondangrejo dengan Berbagai Skenario}

Base model yang telah terkalibrasi dan dinyatakan valid kemudian dibuatkan model Simpang Exit Toll Gondangrejo dengan berbagai skenario yang telah direncanakan. Simpang Exit Toll Gondangrejo dimodelkan dengan dua perlakuan berbeda yaitu skenario 1 dilakukan perlakuan berupa perubahan pada pengaturan fase pergerakan menjadi pemutusan cepat (early cut-off). Selain itu dilakukan juga penyesuaian pada waktu siklus sinyal dengan 
pengaturan fase pergerakan yang baru dan skenario 2 dilakukan perubahan sistem pengoperasian lampu lalu lintas menjadi semi actuated controller, cara kerja sistem semi actuated controller dalam penelitian ini yaitu apabila tidak ada kendaraan dari arah timur dalam satu siklus, maka fase 3 akan tetap merah dan hanya terjadi dua fase pergerakan yaitu fase 1 dan 2. Detektor dipasang pada lengan simpang timur untuk mendeteksi ada tidaknya kendaraan yang melintas.

\section{Perbandingan antara Kinerja Model Simpang Exit Toll Gondangrejo Eksisting dengan semua skenario} Perbandingan antara kinerja model Simpang Exit Toll Gondangrejo eksisting dengan semua skenario pada jam puncak dan tidak puncak berupa panjang antrian, waktu tempuh dan tundaan akan ditampilkan pada gambar dibawah ini.
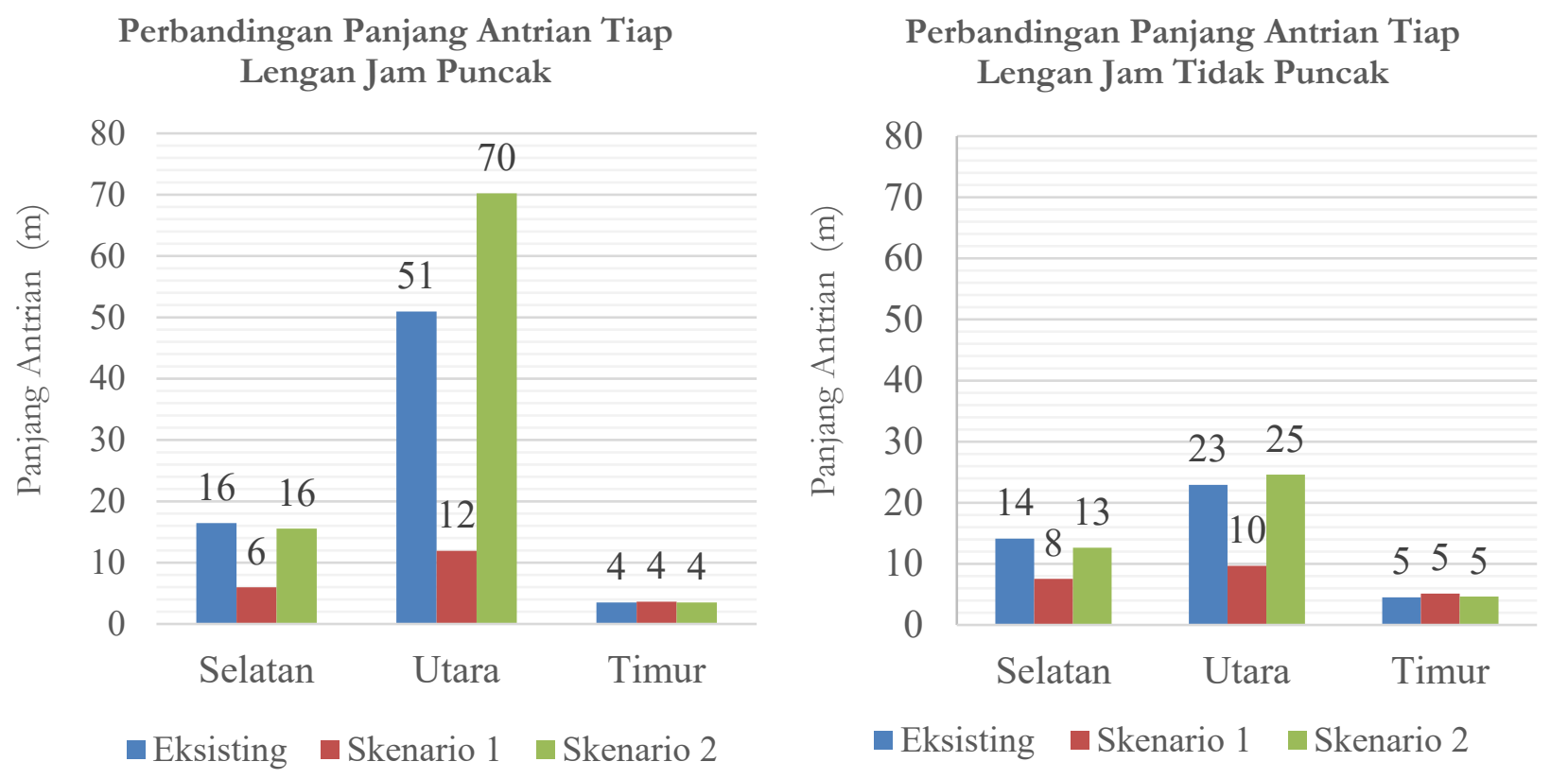

Gambar 1. Perbandingan panjang antrian antara model Simpang Exit Toll Gondangrejo eksisting dengan setiap skenario pada jam puncak dan tidak puncak

Gambar 1 menunjukan bahwa terjadi perubahan panjang antrian pada model Simpang Exit Toll Gondangrejo skenario 1 dan skenario 2 jika dibandingkan dengan eksisting pada jam puncak, yaitu lengan simpang selatan berubah dari 16 meter menjadi 6 meter pada skenario 1 dan tetap pada 16 meter pada skenario 2, lengan simpang utara berubah dari 51 meter menjadi 12 meter meter pada skenario 1 dan berubah menjadi 70 meter pada skenario 2 dan lengan simpang timur tetap pada 4 meter pada skenario 1 dan 2. Sedangkan pada jam tidak puncak lengan simpang selatan berubah dari 14 meter menjadi 8 meter pada skenario 1 dan berubah menjadi 13 meter pada skenario 2, lengan simpang utara berubah dari 23 meter menjadi 10 meter meter pada skenario 1 dan berubah menjadi 75 meter pada skenario 2 dan lengan simpang timur tetap pada 5 meter. 


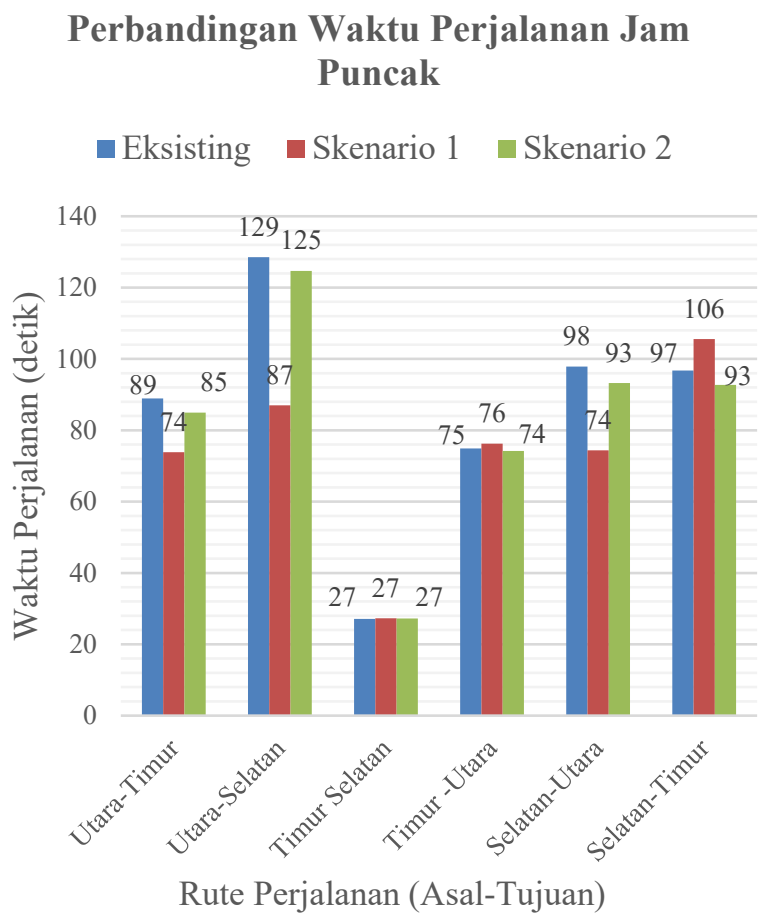

\section{Perbandingan Waktu Perjalanan Jam Tidak Puncak}

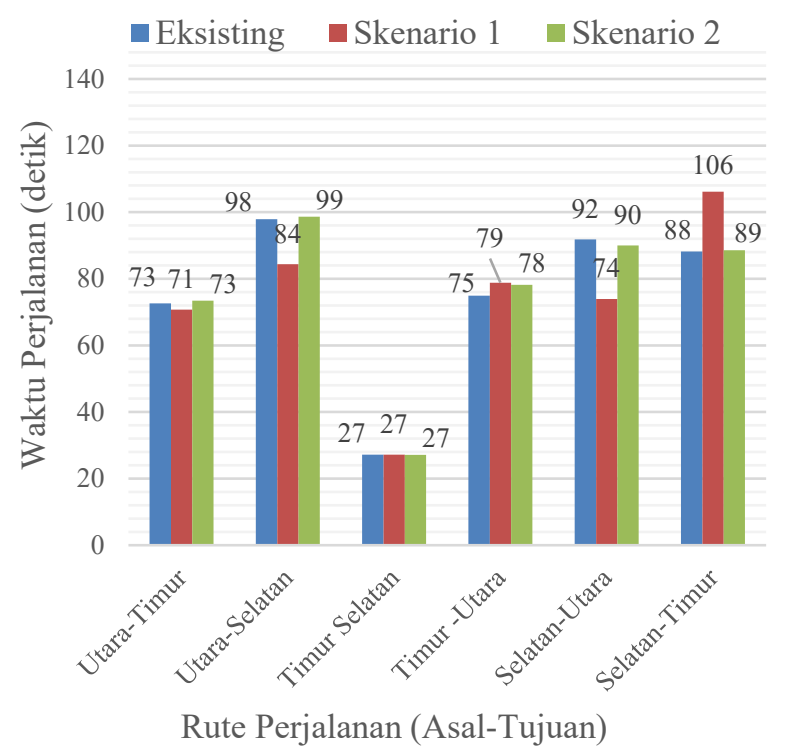

Gambar 2. Perbandingan waktu perjalanan antara model Simpang Exit Toll Gondangrejo eksisting dengan setiap skenario pada jam puncak dan tidak puncak

Gambar 2 menunjukan bahwa terjadi perubahan waktu perjalanan pada model Simpang Exit Toll Gondangrejo skenario 1 dan skenario 2 jika dibandingkan dengan eksisting pada jam puncak, yaitu Utara - Timur berubah dari 89 detik menjadi 74 detik pada skenario 1 dan berubah menjadi 85 detik pada skenario 2 Utara - Selatan berubah dari 129 detik menjadi 87 detik pada skenario 1 dan berubah menjadi 125 detik pada skenario 2, Timur - Selatan tetap 27 detik pada skenario 1 dan 2, Timur - Utara berubah dari 75 detik menjadi 76 detik pada skenario 1 dan berubah menjadi 74 detik pada skenario 2, Selatan - Utara berubah dari 98 detik menjadi 74 detik pada skenario 1 dan tetap 93 detik pada skenario 2, Selatan - Timur berubah dari 97 detik menjadi 106 detik pada skenario 1 dan berubah menjadi 93 detik pada skenario 2. Sedangkan pada jam tidak puncak waktu perjalanan Utara - Timur Tetap berubah dari 73 detik menjadi 71 detik pada skenario 1 dan tetap 73 detik pada skenario 2, Utara - Selatan berubah dari 98 detik menjadi 84 detik pada skenario 1 dan berubah menjadi 99 detik pada skenario 2, Timur - Selatan tetap 27 detik pada skenario 1 dan 2, Timur - Utara berubah dari 75 detik menjadi 79 detik pada skenario 1 dan berubah menjadi 78 detik pada skenario 2, Selatan - Utara berubah dari 92 detik menjadi 74 detik pada skenario 1 dan berubah menjadi 90 detik pada skenario 2, Selatan - Timur berubah dari 88 detik menjadi 106 detik pada skenario 1 dan berubah menjadi 89 detik pada skenario 2 


\section{Perbandingan Tundaan Simpang Jam Puncak}

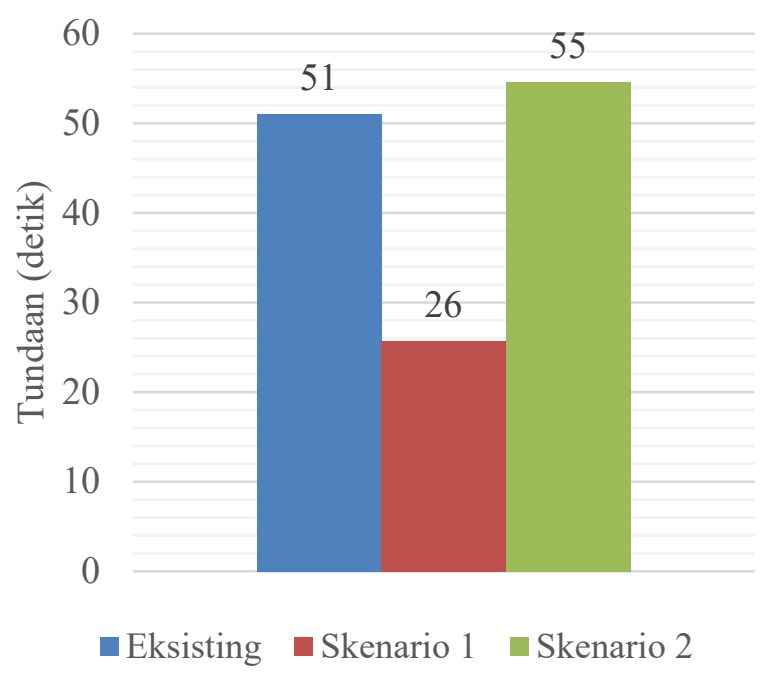

\section{Perbandingan Tundaan Simpang Jam} Tidak Puncak

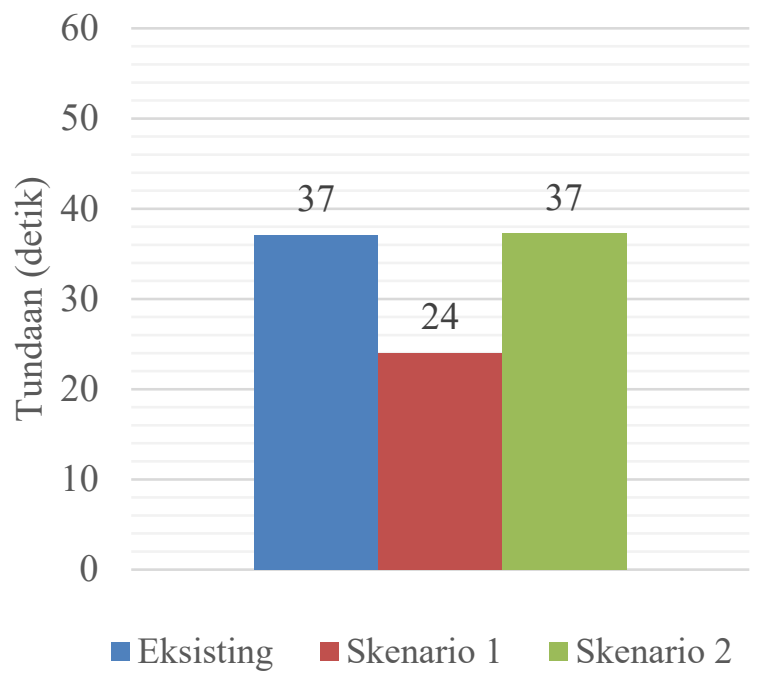

Gambar 3. Perbandingan tundaan antara model Simpang Exit Toll Gondangrejo eksisting dengan setiap skenario pada jam puncak dan tidak puncak

Gambar 3 menunjukan adanya perubahan nilai tundaan pada model Simpang Exit Toll Gondangrejo skenario 1 dan skenario 2 jika dibandingkan dengan eksisting pada jam puncak, yaitu dari 51 detik menjadi 26 detik pada skenario 1 dan menjadi 55 detik pada skenario 2. Sedangkan pada jam tidak puncak tundaan berubah dari 37 detik menjadi 24 detik pada skenario 1 dan tetap 37 detik pada skenario 2 .

\section{SIMPULAN}

Dapat ditarik kesimpulan berupa beberapa hal yang didasarkan pada hasil analisis dan pembahasan terhadap kinerja model Simpang Exit Toll Gondangrejo eksisting dan berbagai skenario, sebagai berikut:

1. Base model Simpang Exit Toll Gondangrejo eksisting sudah tervalidasi dan terkalibrasi, dibuktikan dengan hasil perbandingan data volume arus lalu lintas, panjang antrian dan waktu perjalanan yang tidak berbeda jauh baik pada kondisi aktual ataupun saat telah dimodelkan di program simulasi PTV VISSIM.

2. Perbandingan kinerja model Simpang Exit Toll Gondangrejo eksisting dengan skenario 1 menunjukan bahwa sistem pengaturan lalu lintas pemutusan cepat (early cut-off) memberi pengaruh signifikan terhadap peningkatan kinerja Simpang Exit Toll Gondangrejo dikarenakan waktu hijau pada sinyal pendekat jalan mayor lebih panjang.

3. Perbandingan kinerja model Simpang Exit Toll Gondangrejo eksisting dengan skenario 2 menunjukan bahwa kefektifan penerapan sistem Semi Actuated Controller sangat bergantung pada volume kendaraan dan jumlah kendaraan yang keluar dari jalan minor.

\section{UCAPAN TERIMAKASIH}

Terima kasih penulis haturkan kepada Bapak Budi Yulianto S.T., M.Sc.. Ph.D. dan Bapak Setiono, S.T., M.Sc.. sebagai dosen pembimbing yang sudah bersedia membimbing penulis dalam penelitian ini. Terima kasih juga penulis ucapkan kepada keluarga dan rekan penulis yang telah memberi dukungan hingga selesainya tugas akhir ini.

\section{REFERENSI}

Department for Transport, 2020, “TAG UNIT M3. 1 Highway Assignment Modelling”, Transport Appraisal and Strategic Modelling (TASM) Division, Department for Transport, London.

Departemen Pekerjaan Umum,1997, "Manual Kapasitas Jalan Indonesia”, Direktorat Jendral Bina Marga, Jakarta. Irawan, M. Z., \& Putri, N. H., 2017, "Kalibrasi Vissim Untuk Mikrosimulasi Arus Lalu Lintas Tercampur pada Simpang Bersinyal (Studi Kasus: Simpang Tugu, Yogyakarta). Jurnal Transportasi Multimoda Vol. 13 No. 3 pp. 97-106.

Yulianto, B. \& Setiono, 2013, “Kalibrasi dan Validasi Mixed Traffic VISSIM Model”, Media Teknik Sipil. 